\title{
TWO NEW SPECIES OF Fannia ROBINEAU-DESVOIDY (DIPTERA, FANNIIDAE)
}

\author{
COURI, M. S. \\ Departamento de Entomologia, Museu Nacional, Quinta da Boa Vista, \\ CEP 20940-040, Rio de Janeiro, RJ, Brazil \\ Research Fellow of Conselho Nacional de Desenvolvimento Científico e Tecnológico, CNPq \\ Correspondence to: Márcia S. Couri, Museu Nacional, Quinta da Boa Vista, \\ CEP 20940-040, Rio de Janeiro, RJ, Brazil, e-mail: mcouri@attglobal.net \\ Received May 6, 2003 - Accepted September 24, 2003 - Distributed November 30, 2004 \\ (With 10 figures)
}

\begin{abstract}
Fannia Robineau-Desvoidy is known from 63 neotropical species, 24 of them with occurence in Rio de Janeiro State. Two new species from Rio de Janeiro State are added to the genus: F. tibialis, sp. $\mathrm{n}$ and $F$. unica, sp. n. Male specimens of both are described. Morphological characters and terminalia are illustrated. Each species is briefly discussed.
\end{abstract}

Key words: Fanniidae, Fannia, F. tibialis, sp. n, F. unica, sp. n., taxonomy.

\section{RESUMO}

\section{Duas espécies novas de Fannia Robineau-Desvoidy (Diptera, Fanniidae)}

Fannia Robineau-Desvoidy é conhecida por apresentar 63 espécies neotropicais, 24 delas com ocorrência no Estado do Rio de Janeiro, sendo que duas novas espécies procedentes desse Estado foram acrescidas aos gêneros: F. tibialis, sp. n. e $F$. unica, sp. n. São descritos os exemplares machos de ambas as espécies, cujos caracteres morfológicos e terminália são ilustrados. Também é apresentada breve discussão sobre cada uma das novas espécies.

Palavras-chave: Fanniidae, Fannia, F. tibialis, sp. n., F. unica, sp. n., taxonomia.

\section{INTRODUCTION}

The Fanniidae family, which occurs in all zoogeographic regions, is known from 4 genera and 267 species. In the Neotropical region, the family is known from 2 genera: Euryomma Stein and Fannia Robineau-Desvoidy, respectively with 9 and 63 species (Carvalho et al., 1993), of which 24 occur in Rio de Janeiro State.

One of the diagnostic characters at the species level in male Fannia is the pre-apical bristle at the posteroventral surface of hind femur, which can vary from a single bristle to a cluster of bristles, often at distinct elevations (Chillcott, 1960). Couri (in preparation) is elaboratiing an illustrated key to these species.

The aim of this paper is to add two new species from Rio de Janeiro State to Fannia: F. tibialis sp. n. and F. unica, sp. n. Both are described from male holotypes, and both show a peculiar cluster of bristles on the hind femur.

\section{MATERIAL AND METHODS}

The material examined belongs to Museu Nacional, Rio de Janeiro (Brazil) collection (MNRJ).

The terminalia of both holotypes were prepared in a solution of potassium hydroxide $10 \%$, in a waterbath, for ten minutes. They were then dissected in glycerol, drawn and packed in microtubing with glycerol, and fixed by a pin together with the specimen.

\section{Fannia tibialis, sp. nov.}

Color. Brown with grey pollinosity. Head with frons, face, fronto-orbital plate and gena silver; antenna with brown pedicel and brown flagellum 
with grey pollinosity, arista dark yellow, lighter on basal third; palpus dark-brown. Mesonotum brown, with 2 dark-brown lateral areas. Calypters yellowish with yellow margins; halter brown with yellowish areas; wing slightly infuscated. Legs brown; pulvillus yellowish white; claw yellow on basal half and black on apical. Abdomen with tergites 1+2-4 with darkyellow lateral marks.

Length: Male body: $5.8 \mathrm{~mm}$; wing, $6.0 \mathrm{~mm}$.

Head. Eye bare, antero internal facets larger; holoptic, interocular space about 0.11 of head width at level of anterior ocelli. Twelve pairs of long frontal setae. Inner and outer vertical setae delicate. Ocellar seta long, similar in length to the frontals. Antenna inserted below middle of eyes; flagellum about twice as long as pedicel. Arista pubescent (short). Vibrissa long and strong; 2-3 supravibrissal setulae.

Thorax. Acrostichal setulae in 3-4 disarranged rows, pre-scutelar pair developed; dorsocentral setae $2: 3 ; 2$ strong humerals; 1 post-humeral; 1 presutural and 2 post-sutural intra-alars; 2 supraalars. Scutellum with one sub-basal and one apical pair of bristles (both broken). Notopleuron with two similar long bristles. Anepisternum with a row of about 10 bristles and many long ground cilia. Calypter about 1.6 less than the superior. Fore femur with a complete posterodorsal row of bristles, dorsal surface with a row of bristles on apical two thirds. Fore tibia with one pre-apical dorsal and 2 very short apical ventral. Mid femur with an anterodorsal row of short bristles, a comb-like anteroventral row on apical third, a posteroventral row on apical fourth. Mid tibia swallowed on basal third, 2 anterodorsal bristles on apical third, ventral cilia on middle third (Fig. 1). Hind femur enlarged preapically in a distinct swelling, anteroventral surface of the swelling with 4 long bristles (Fig. 2), posteroventral surface with a tuft of many bristles apically curled (Fig. 3). Hind tibia with 2 submedian anteroventral bristles, a short anterodorsal row on apical third, and a pre-apical dorsal.

Abdomen. Tergites 2-5 with lateral strong bristles. Tergite 5 with a row of apical bristles. Sternite 5 with stronger bristles closer to anterior margins.

Terminalia. Lost.

\section{DISCUSSION}

F. tibialis can be easily distinguished from the other Fannia males by the bristling of the mid and hind femora and by the bristling and shape of mid tibia. In the Albuquerque et al. (1981) key to identification, the species is close to F. tumidifemur Stein, 1911, and can be distinguished by the bristles on the swelling of hind femur; 4 long bristles with straight apex in $F$. tibialis and a tuft of long bristles with hooked apex in F. timidifemur.

Material examined: Holotype male: Brazil: Estado do Rio de Janeiro, Friburgo, I.1946, Wygodzinsky col.

\section{Fannia unica sp. nov.}

Color. Generally brownish. Brown with grey pollinosity. Head with frons, face, fronto-orbital plate and gena brown, with dark-golden pollinosity; antenna with flagellum brown, with golden pollinosity; pedicel yellowish-brown with no pollinosity; arista brown on apical two thirds and yellow on basal third; palpus yellow. Mesonotum with no traces of vitta, dark-brown until middle third of scuttum and brown with a faint grey pollinosity on apical third of scuttum and scutellum. Calypters yellowish-white; halter yellow; brownish at tip of knob. Wings slightly infuscated. Legs yellow. Abdomen with tergites $1+2$ and 3 with disco-lateral golden-brownish marks.

Length: Male body: $6.0 \mathrm{~mm}$; wing, $6.2 \mathrm{~mm}$.

Head. Eyes bare, facets of same size; holoptic, interocular space a little larger than the diameter of anterior oceli at this level. About 12 pairs of long frontal setae. Inner and outer vertical seta delicate. Ocellar seta a little shorter than the frontals. Antenna inserted below middle of eyes; flagellum about 2.2 of pedicel. Arista shortly pubescent. Vibrissa strong and long; 2-3 supravibrissal setulae.

Thorax. Acrostichal setulae in 3-4 disarranged rows, pre-scutelar pair developed; dorsocentrals setae $2: 3 ; 2$ strong humerals; 1 post-humeral; 1 presutural and 2 posy-sutural intra-alars; 2 supraalars. Scutellum with one short pair of sub-basal bristles, one apical long, about 1.6 times the length of the sub-basal. Notopleuron with two similar long bristles. Anepisternum with a row of about 10 bristles, 2 of them long and strong, one inserted at the basal third of the row and the other at the apical third; with many long, ground cilia. Calypter about 1.7 less than the superior. Fore femur with a row of anterodorsal and posterodorsal bristles; posteroventral row on apical half. Fore tibia with pre-apical dorsal and 2 apical ventrals. Mid femur with a row of short anterodorsal, an anteroventral, a ventral, and a posteroventral series a little longer than the anterodorsal row. Mid tibia with an an- 
terior median bristle and many hair-like ventral setulae, a dorsal pre-apical (Fig. 4). Hind femur with a posterodorsal bristle on apical third, and a sub-median tuft of long bristles apically curled on posteroventral surface (Fig. 5). Hind tibia with an anteroventral and an anterodorsal row of bristles inserted on middle third, dorsal surface with a median long bristle and a pre-apical one.

Abdomen. Tergites 4 e 5 with a row of apical bristles. Sternite 5 with stronger bristles closer to the anterior margins (Fig. 6).

Terminalia. Cercal plate rather short and broad, a little concave; surstylus long and fine, with a supramedian swelling; baciliform process flattened (Fig. 7); ninth sternum slender, with a short lateral process (Fig. 8).

Discussion. In the Albuquerque et al. (1981) key to identification, $F$. unica is close to $F$. tumidifemur (Stein, 1911), but can be distinguished by the yellow palpus and absence of a distinct preapical swelling on hind femur in F. unica, and by the brown palpus and presence of a distinct pre-apical swelling on hind femur in F. tumidifemur.

Material examined: Holotype male: BRAZIL: Rio de Janeiro State, Rio de Janeiro, Grajaú, 8.xii.1940, Lopes \& Oliveira col.
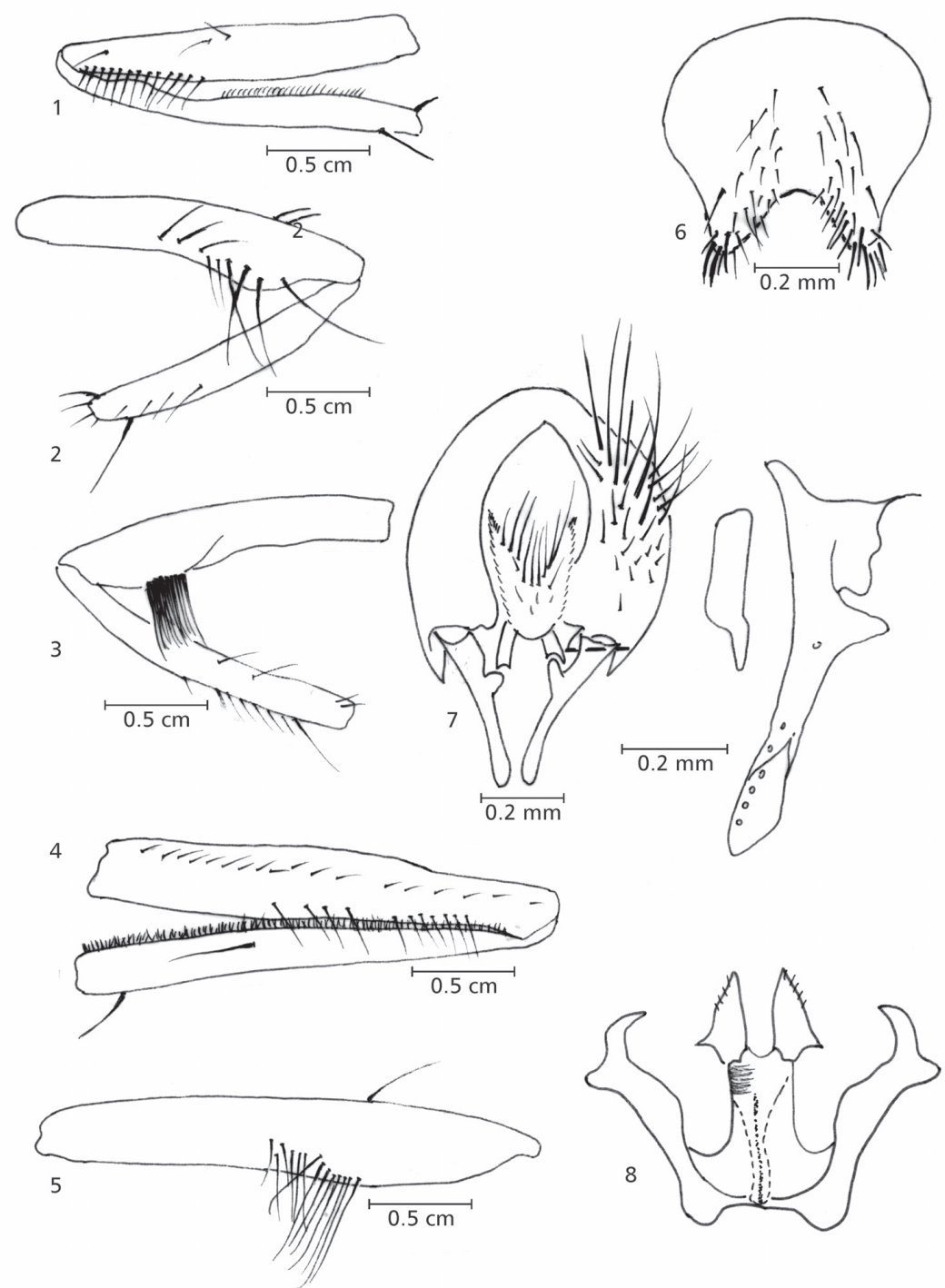

Figs. 1-8 - 1-3: Fannia tibialis, sp. n., male; 1: mid femur and tibia, anterior view; 2: hind femur and tibia, anterior view; 3 : hind femur and tibia, posterior view; 4-8: Fannia unica, sp. n., male; 4: mid femur and tibia, anterior view; 5: hind femur, posterior view; 6: sternite 5; 7: cercal plate and surstyli, lateral view; 8: phallic complex, dorsal view. 
Acknowledgements - The author is grateful to CNPq for a research grant (process number 300386/80-0) that funded the project.

\section{REFERENCES}

ALBUQUERQUE, D. O., PAMPLONA, D. \& CARVALHO, C. J. B., 1981, Contribuição ao conhecimento dos Fannia R.-D., 1830 da região neotropical (Diptera, Fanniidae). Archos Mus. Nac., 56: 9-34.
CARVAlhO, C. J. B., PONT, A. C., COURI, M. S. \& PAMPLONA, D., 1993, Parte I. Fanniidae - I-29. In: A catalogue of the Fanniidae and Muscidae (Diptera) of the neotropical region. Sociedade Brasileira de Entomologia, São Paulo.

CHILlCOTT, J. G., 1960, A Revision of the nearctic species of Fanniinae (Diptera: Muscidae). Can. Ent., 92(14): 295.

COURI, M. S. (in preparation), An illustrated key to male Fannia Robineau-Desvoidy with a pre-apical bristle cluster on hind femur (Diptera, Fanniidae). 